\title{
TERRESTRIAL DEVELOPMENT IN THE TASMANIAN FROG, BRYOBATRACHUS NIMBUS (ANURA: MYOBATRACHINAE): LARVAL DEVELOPMENT AND A FIELD STAGING TABLE
}

\author{
by Nicola Mitchell and Roy Swain
}

(with three tables and one text-figure)

\begin{abstract}
Mitchell, N. \& Swain, R. 1996 (30:vi): Terrestrial development in the Tasmanian frog, Bryobatrachus nimbus (Anura: Myobatrachinae): larval development and a field staging table. Pap. Proc. R. Soc. Tasm. 130(1): 75-80.

https://doi.org/10.26749/rstpp.130.1.75 Department of Zoology, University of Tasmania, Box 252C, GPO Hobart,

Tasmania, Australia 7001.

The moss froglet Bryobatrachus nimbus is a recently described terrestrial breeding and direct developing anuran from southwestern Tasmania. A 17-stage table based on changes in external morphology was developed in order to calculate development rates and larval lifespan. This staging demonstrated that development was not predominantly intracapsular as earlier reported. Instead, larvae hatch from the capsule two to three months after oviposition and continue development in the nest within a homogenous, capsule-derived fluid. This reproductive mode was previously known in Australia only in the Geocrinia rosea complex from souchwestern Australia. This paper describes the larval life-history of a subalpine population and presents data on clutch size, ovum and capsule diameters and the duration of larval development. Capsule size is almost twice that recorded for any other Australian anuran, while the larval lifespan is the longest known for any terrestrial breeding Australian species. Metamorphosis occurs approximately 12 months after oviposition.

Keywords: Amphibia, Bryobatrachus, direct development, life history, staging, terrestrial breeding, Tasmania.
\end{abstract}

\section{INTRODUCTION}

The moss froglet, Bryobatrachus nimbus Rounsevell, Ziegeler, Brown, Davies and Littlejohn, 1994, was discovered late in 1992, following the reporting of an unusual frog call in heathland at several high altitude sites in southwestern Tasmania (Rounsevell et al. 1994). It is the first addition to the Tasmanian anuran fauna since the description of the Tasmanian Tree Frog, Litoria burrowsae (Scott 1942), and is only the third endemic species of the 11 Tasmanian anurans now known. Its discovery is significant, because both the habitat occupied and the reproductive mode exhibited are unique amongst the local fauna and are shared by very few mainland Australian species.

Bryobatrachus nimbus inhabits cloud forest in subalpine heath and lowland rainforest in the wet southwest of the island and is the sole Tasmanian anuran in which the life cycle is entirely terrestrial. The adults are cryptic, and females deposit small clutches of large eggs in nests built into moss, lichen or peat in a spring/summer breeding season; larvae complete development in the nest without feeding and are direct-developing (Rounsevell et al. 1994).

Staging tables are useful in ascertaining the rate and duration of larval development, both of which were unknown for $B$. nimbus at the commencement of our study. Stages $20-26$ of the standard anuran staging table developed for aquatic species by Gosner (1960) are not applicable to any myobatrachine in which the life history has been described, since these all lack external gills and exhibit differences in the development of the eye and oral suckers (Gollman \& Gollman 1991). Furthermore, the large yolk sacs characteristic of direct developing species can mask some of the stages defined by Gosner (Gollman 1991). De Bavay (1993) has produced a mericulous staging table for the limnodynastine Kyarranus sphagnicolus, which follows Gosner's scheme to Stage 19 and redefines and reduces the numbers of stages thereafter.
We have developed a simple 17-stage table based on external features (visible to the naked eye or under low magnification), as a means of staging larval development in B. nimbus under field conditions, and have used this table to determine rates of development in both field and laboratory conditions. We also describe the larval lifehistory of $B$. nimbus and report data on clutch size, ovum and capsule diameters and the duration of larval development in a subalpine, heathland population.

\section{METHODS}

\section{Study Site}

The study site was the type locality of $B$. nimbus in the Hartz Mountains National Park. It consists of a poorly drained, subalpine moorland at $900 \mathrm{~m}$, immediately north of Lake Esperance, and covers approximately 5 ha. This sice contains the only readily accessible population of the 15 populations reported by Ziegeler (1994). Vegetation communities and climatic patterns have been described by Rounsevell et al. (1994). In the period 2/10/94 to 29/2/96 approximately 40 visits, each of $1-3$ days duration, were made to the site.

\section{Staging of Larvae}

Two clutches of ten eggs newly deposited in December 1994 were transported intact in their moss nests to the laboratory in Hobart. Clutches were transferred to glass petri dishes, sprayed with distilled water and placed in a glass desiccator and maintained at $16( \pm 1)^{\circ} \mathrm{C}$. Manually controlled lighting provided a photoperiod regime of approximately $12 \mathrm{~h}$ light: $12 \mathrm{~h}$ dark. Larvae were sprayed twice weekly with distilled water; at front limb emergence they were provided with substrate (moistened paper towel) and immersed in amphibian Ringer's solution (Hoar \& Hickman 1975). 
Larvae were photographed using a $35 \mathrm{~mm}$ camera attached to a Zeiss Stemi SV 11 stereo microscope, initially twiceweekly, and after longer intervals as development progressed. Individual larvae were periodically selected to illustrate stages, killed by an overdose of MS222 and preserved in Tyler's fixative (Tyler 1962). Drawings of preserved specimens were made from observations through a stereo microscope. Examination of these specimens, and analysis of photographic records and developmental notes from field and laboratory-reared larvae allowed the identification of 17 distinct stages. Only those stages that could be reliably determined by the naked eye or by a low power lens were used to develop the staging table, although numerous intermediate stages could be identified in the laboratory.

\section{Measurement of Clutch, Ovum, Capsule and Larval Size}

All clutches located in the field were marked by tagging adjacent vegetation; the number of visible eggs or larvae was counted and larval features described. Eggs were not handled, in order to eliminate human interference as a cause of mortality; hence, only surface eggs were counted and described. In order to correct for underestimates of clutch size, the number of eggs in eight clutches that were removed for laboratory studies was estimated in the field and, subsequently, compared with the number determined by laboratory examination. This revealed that clutch sizes were underestimated by between one and four eggs; to provide more realistic estimates of clutch sizes, field counts were adjusted as follows: one egg was added to estimates of eight eggs or fewer, and two eggs were added to all larger estimates. Occasionally, we were confident that we could see all the eggs in a clutch, and these estimates were not adjusted. Clutches discovered after capsule degradation were not included in the estimates of clutch size, as larvae had often sunk to the base of the nest and were difficulc to discern.

Accurate measurements of ovum and larval size could only be obtained in the laboratory; they were made by using a stereo microscope and an eyepiece micrometer, under either distilled water or Ringer's solution, according to their stage. Larvae reared at 11,16 and $21^{\circ} \mathrm{C}$ were measured every three to four days. Size at each stage was determined from larvae reared at 11 and $21^{\circ} \mathrm{C}$. Embryos were measured along their maximum axis and, beyond Stage 9, snout-vent lengths were also obtained. Capsule diameters were measured to Stage 10, since some tadpoles remain within the capsule to this point.

Vernier callipers were used in the field to measure external capsule diameters of newly deposited eggs to the nearest $0.05 \mathrm{~mm}$, especially if eggs were particularly accessible or of an extreme size. Ovum and capsule diameters of six newly deposited clutches were measured in the laboratory on the same evening that they were removed from the field.

\section{Length of the Larval Period}

Most clutches discovered were re-examined at each extended field visit; in this way development rates and the length of the larval lifespan could be determined.

\section{RESULTS}

\section{Field Staging Table}

Table 1 lists the diagnostic features of each of the 17 stages identified for $B$. nimbus, while figure 1 illustrates these stages. Some features of several stages can only be identified with the aid of a hand lens, but broader characteristics, such as a typical posture, should allow the identification of any stage in the field. Onset of heartbeat (Gosner Stage 19) and blood circulation in the tail become apparent between Stages 11 and 12 and Stages 12 and 13 respectively and, thus, were not used as diagnostic criteria. Adult B. nimbus exhibit three pairs of distinct dark-brown or black dorsal markings; the first pair fuses between the eyes (chevron shaped), and two other pairs occur in the scapula and coccygeal regions respectively (Rounsevell et al. 1994); these are the markings referred to at Stage 15 in table 1.

In most respects, developmental stages of $B$. nimbus parallel those determined by de Bavay (1993) for Kyarranus sphagnicolus. To facilitate comparison, table 1 identifies the correspondence between stages in $B$. nimbus and $K$. sphagnicolus.

Mean sizes at all stages of larval development are listed in table 2. Larvae in the $11^{\circ} \mathrm{C}$ treatment were not retained beyond Stage 11, because of concern about maintaining larvae in artificial conditions for an indeterminate period. Sizes for later stages were derived from the faster developing larvae maintained at $21^{\circ} \mathrm{C}$ (table 2). The rate of laboratory development at $11^{\circ} \mathrm{C}$ was comparable to development rates in the field (N. Mitchell, pers. obs.). The measure of larval size was dependent on the posture of each individual, and variability in posture was pronounced during the stages prior to capsule degradation (Stages 7 to 10 ). Hence, the variance estimates of larval length increase beyond Stage 6 .

\section{Ovum, Capsule and Clutch Size}

Of 62 clutches in which egg number could be counted, estimates of clurch size ranged from 4-16 eggs (mean \pm SE $=9.1 \pm 0.39$ ). Table 3 shows egg number, together with mean ovum and mean external capsule diameters for six of the eight newly deposited clutches that were returned to the laboratory. Capsule diameters were quite variable, borh within and between clutches, presumably due in part to differences in hydration state, but it is clear that the cggs of $B$. nimbus are characterised by the provision of a large egg capsule (table 3 ).

\section{Description of Larval Development}

Bryobatrachus nimbus clutches were located throughout the period November 1994 to March 1995. With the single exception of a nest built into pear beneath lichen, all clutches were found in small nests $(20-70 \mathrm{~mm}$ in diameter) concealed within moss. Usually most eggs were distributed in a single horizontal surface layer overlying a few eggs that filled the nest base. As development progressed, individual egg capsules lost their integrity and their horizontal diameter increased. Eventually, the seams between capsules vanished and a homogenous gelatinous mass was formed. Larvae would then sink to the base of the nest. 


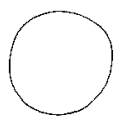

Stage 1

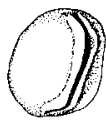

Stage 4

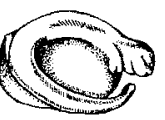

Stage 7
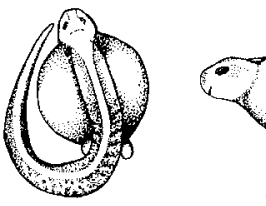

Stage 10

Stage 9

FIG. 1 - Stages in the development of Bryobatrachus nimbus.

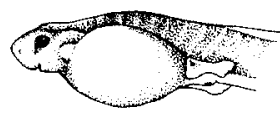

Stage 11

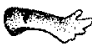

hindlimb Stage 12

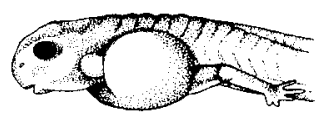

Stage 13

Stage 14
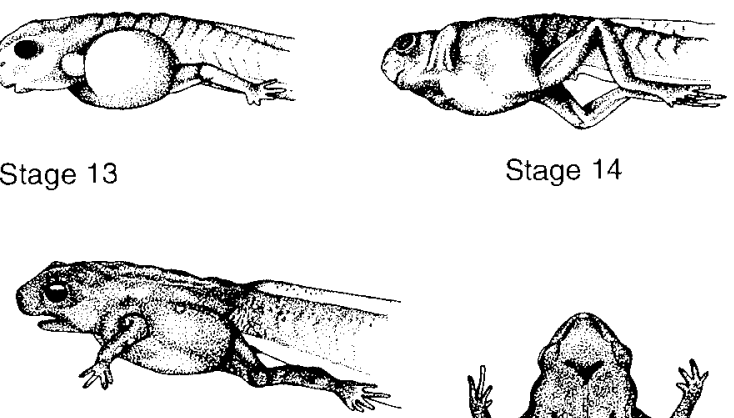

Stage 15

Stage descriptions of larval Bryobatrachus nimbus

\begin{tabular}{|c|c|c|c|c|}
\hline Stage & Diagnostic features & $\begin{array}{l}\text { de Bavay } \\
\text { equivalent }\end{array}$ & Stage* & Diagnosric fearures \\
\hline
\end{tabular}

1 - stage begins at oviposition

- egg unpigmented - cream or grey-cream; surface fearureless

$2^{\dagger} \cdot$ mid-late gastrula

- egg grey, with cream poles

$3^{\dagger}$-yolk-plug developed

- egg grey/cream, with dark poles

$4^{\dagger} \cdot$ neural folds form to outline neural plate

- vitellus slightly ovoid

5 - embryo visible as a ridge on egg surface

- tail rudiment and somites ${ }^{\dagger}$ visible

- vitelline membrane ${ }^{\dagger}$ distinct

6 - embryo length exceeds egg diameter

- head well differentiated

- tail about as long as and bent $90^{\circ}$ to body

- tail usually curled around yolk; about twice length attached body

- anal pore evident

- capable of strong writhing

8 - Larvae "C" shaped; tail no longer flush to yolk; about 2.5 times length of attached body

- paired, circular hind buds prominent

- opaque tail fin formed

- mouthparts ${ }^{\dagger}$ just visible

- vitelline membrane may not be intact

$9 \quad$ - grey eye pigmentation developing

- hind buds ovoid

- mourhparrs ${ }^{\dagger}$ discince

- vicelline membrane broken down

- larvae may be free of capsule
$1-7$

$8-10$

$11-12$

$13-15$

$16-17$

$19-19 b$

$20-22$

Stage 16 capsule

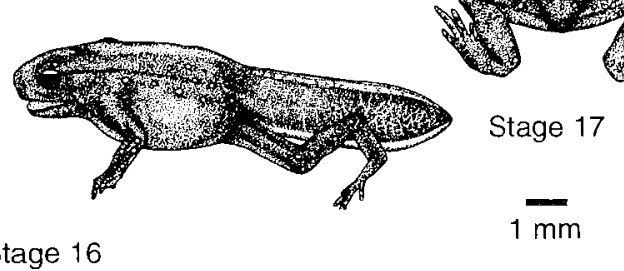

equivalent

- yolk-sac vanished (incorporated into body)

- eye appears entirely black

- hind bud expanded to a "paddle" $\dagger$

- larvae may be free of capsule

11 - eye "surfaced"

- nostrils ${ }^{\dagger}$ just visible

- digit indentations ${ }^{\dagger}$ developed on hind buds;

buds similar length to head

- small front limb swellings ${ }^{\dagger}$

- tail reticulation ${ }^{\dagger}$ developing

- larvae free of capsule

12 - individual digits discernible on hind limb 29-30

- upper half of iris ${ }^{\dagger}$ gold

13 - distince bend to hind limbs

- fronc bud swellings prominent

- cail reciculation pronounced

14 - prominent front limb bulge; digits ${ }^{\dagger}$ visible beneath skin

- pronounced bend ro hind limbs;

total bent-leg lengrh similar co SVL

15 - front linbs emerged

- dorsal spotting developing

- characteristic dark dorsal marks ${ }^{\dagger}$ developing

16 - dorsal colouring developing

- tail re-absorption occurring

17 - cail completely reabsorbed

- adult colours emerged

$25-26$

- dorsal spots vanished or vanishing

\footnotetext{
* Larvae have reached a developmental stage when $50 \%$ of the diagnostic features of that stage have become evident (de Bavay 1993)

$\dagger$ Indicates stages or features requiring low power magnification for identification. $¥$ Snout vent length.
} 
TABLE 2

Dimensions of ova, larvae and capsules, and snout vent length (SVL) of Bryobatrachus nimbus larvae at each stage

\begin{tabular}{|c|c|c|c|c|c|c|c|}
\hline Stage & \multicolumn{2}{|c|}{$\begin{array}{l}\text { Mean ovum SE } \\
\text { or larval } \\
\text { lengrh }(\mathrm{mm})\end{array}$} & $\begin{array}{l}\text { Mean } \\
\text { SVL } \\
(\mathrm{mm})\end{array}$ & SE & $\begin{array}{c}\text { Mean } \\
\text { capsule } \\
\text { diameter } \\
(\mathrm{mm})\end{array}$ & $S E$ & $n$ \\
\hline 1 & 3.9 & 0.11 & & & 11.3 & 0.30 & 18 \\
\hline 2 & 4.3 & 0.06 & & & $\mathrm{NA}$ & & \\
\hline 3 & NA & & & & 11.8 & 0.31 & 18 \\
\hline 4 & 4.3 & 0.06 & & & 12.7 & 0.31 & 18 \\
\hline 5 & 4.8 & 0.05 & & & 13.4 & 0.30 & 19 \\
\hline 6 & 5.6 & 0.08 & & & 14.0 & 0.39 & 18 \\
\hline 7 & 7.6 & 0.19 & & & 16.1 & 0.60 & 17 \\
\hline 8 & 8.6 & 0.26 & & & 17.7 & 0.61 & 18 \\
\hline 9 & 9.4 & 0.16 & & & 21.2 & 0.81 & 16 \\
\hline 10 & 10.0 & 0.21 & 4.7 & 0.07 & 22.5 & 0.72 & 16 \\
\hline 11 & 16.5 & 0.26 & 5.0 & 0.07 & & & 15 \\
\hline 12 & $* 17.3$ & ${ }^{*} 0.38$ & $* 5.0$ & ${ }^{*} 0.10$ & & & ${ }^{*} 10$ \\
\hline 13 & 20.2 & 0.40 & 5.9 & 0.07 & & & 13 \\
\hline 14 & ${ }^{*} 18.4$ & ${ }^{*} 0.42$ & $* 5.2$ & ${ }^{*} 0.07$ & & & $* 8$ \\
\hline 15 & ${ }^{*} 17.9$ & ${ }^{*} 1.29$ & $* 5.9$ & ${ }^{*} 0.13$ & & & $* 8$ \\
\hline 16 & ${ }^{*} 13.1$ & $* 2.17$ & $* 6.3$ & ${ }^{*} 0.16$ & & & $* 8$ \\
\hline 17 & & & $* 7.1$ & ${ }^{*} 0.32$ & & & $* 8$ \\
\hline
\end{tabular}

* identifies measurements from larvae developing at $21^{\circ} \mathrm{C}$; all other measurements are from development at $11^{\circ} \mathrm{C}$.

$\mathrm{NA}=$ measurement not available.

TABLE 3

Clutch sizes, ovum and capsule diameters of six clutches measured in the laboratory at Stage 1 or 2

\begin{tabular}{lcccccc}
\hline $\begin{array}{l}\text { Clurch } \\
\text { number }\end{array}$ & $\begin{array}{c}\text { Clurch } \\
\text { size }\end{array}$ & $\begin{array}{c}\text { Mean ovum } \\
\text { diameter } \\
\text { (mm) }\end{array}$ & SE & $\begin{array}{c}\text { Mean capsule } \\
\text { diameter } \\
\text { (mm) }\end{array}$ & SE & $n^{*}$ \\
\hline 1 & 12 & 4.2 & 0.10 & 11.3 & 0.38 & 9 \\
2 & 10 & 3.6 & 0.13 & 11.4 & 0.51 & 8 \\
3 & 12 & 4.2 & 0.05 & 11.4 & 0.25 & 12 \\
4 & 10 & 4.1 & 0.04 & 13.8 & 0.28 & 10 \\
5 & 11 & 4.0 & 0.07 & 9.6 & 0.39 & 9 \\
6 & 10 & 4.4 & 0.06 & 10.9 & 0.21 & 9 \\
Mean & 11 & 4.1 & 0.05 & 11.4 & 0.21 & 557 \\
\hline
\end{tabular}

* $n$ refers to the number of eggs that were included in the calculation of mean egg and capsule diameters.

The volume of capsular fluid fluctuated during development. Nests examined during dry weeks in summer sometimes contained less than $5 \mathrm{~mm}$ depth of fluid while, in the same nest, capsulat fluid would swell and fill the nest after heavy rain. Larvae usually remained at the base of the nest but were occasionally discovered on the fluid surface. Ac metamorphic climax, only a smear of capsular fluid remained in the nest; metamorphs were often positioned vertically on the nest wall with their tails dangling in the fluid, or else piled upon each other at the nest base. Meramorphs would remain in the nest after tail reabsorption was complete (Stage 17) for 1-2 weeks. Occasionally larger metamorphs were discovered in nests, up to several months after the original metamorphs had vanished.
Early development of eggs (Stages 1-8) was rapid; larvae could be found in these stages between December and March. Nests were frequently under snow during autumn and for much of winter, and development was negligible during this period. Most larvae overwintered ac Stages 911. Development rates did not accelerate until late spring and early summer, when metamorphic climax was approached comparatively rapidly. For example, 11 individuals of a clutch of 13 observed at Stage 12 on 5/1/95 had almost completed metamorphosis (Stage 17) 27 days lacer on $1 / 2 / 95$. Ten froglets left this nest within five days, while one individual was still in the nest on 17/2/95, having recently metamorphosed.

\section{Length of Larval Development}

The larval lifespan of $B$. nimbus approximates 12 monchs. Exact periods of larval development in the field were difficult to determine, as most clutches discovered soon after oviposition were removed for laboratory study, whilst precise dates of metamorphic climax for the remaining clutches were not obtained, due to infrequent field visits in the 1995/ 1996 breeding season. However, a froglet from a clutch discovered at Stage 2 on 22/12/94 was approaching metamorphic climax (i.e. Stage 16) on 7/1/96, indicating a larval life in excess of 12 months. The simultaneous presence of freshly deposited clutches and metamorphs from December to February further supports this conclusion.

\section{DISCUSSION}

Numerous authors have commented upon the remarkable diversity of reproductive modes within the Myobatrachinae (e.g. Littlejohn et al. 1993, Rounsevell et al. 1994). Our study provides yet further support for this conclusion; Bryobatrachus nimbus lies midway along a spectrum of differing degrees of intracapsular development, exemplified at one extreme by the part intracapsular/part aquatic development of most species of Pseudophryne (Jacobson 1963) and at the other by the completely intracapsular development of Arenophryne (Roberts 1984) and Myobatrachus (Roberts 1981).

However, B. nimbus larvae do not undergo intracapsular development to the extent suggested by Rounsevell et al. (1994); hatching occurs well in advance of metamorphosis (around Stage 10), at abour the same stage as in the Geocrinia - laevis complex and later than aquatic developing Crinia signifera larvae (Gollman 1991). The consequence is that 9-10 months of development in B. nimbus is spent as a free-living but non-feeding tadpole within the capsule fluid. Of 29 anuran reproductive modes defined by Duellman \& Trueb (1994), B. nimbus fits mode 15: "eggs hatch into non-feeding tadpoles that complete theit development in the nest". Duellman \& Trueb (1994) recorded this mode in six species: one leptodactylid and one microhylid from South America, and one bufonid and three ranids from Africa, but it is also known for the Geocrinia spp. from southwestern Western Australia (Main 1957, Roberts et al. 1990). Rounsevell et al. (1994) also drew attention to morphological similarities between larval $B$. nimbus and the larvac of two species of the Geocrinia rosea complex, $G$. rosea and G. lutea. 
The apparent restriction of $B$. nimbus to moist, cloud forest habitat (Ziegeler 1994) is consistent with the general, although not exclusive, correlation observed between terrestrial reproductive modes in the Anura and habitats of high atmospheric humidity (eg. Martin 1967, Duellman 1985). It is, presumably, a consequence of the need to retain some moisture within the nest at all times during the prolonged period of larval development. Although southwestern Tasmania experiences an average annual rainfall of $2500 \mathrm{~mm}$ (Gentilli 1972), much of the area may be dry for weeks at a time in summer (Swain et al. 1988). In these circumstances, a large egg capsule may provide valuable insurance against larval desiccation, and mortality of larvae contained within smaller capsules was certainly higher than in those within larger capsules, during a period of consistently dry weather in January/February 1994 (N.Mitchell, pers. obs.). However, a large capsule volume is likely to have other important consequences, perhaps in relation to cold tolerance but particularly for larval respiration. Respiration rates in developing anurans are strongly influenced by the oxygen conductance of the capsule jelly; conductance is determined by the permeability of the jelly, which is about $75 \%$ of that of pure water at the same remperature, and its thickness and surface area (Seymour \& Roberts 1995).

Several staging tables based on modifications of that of Gosner (1960) have been developed for myobatrachines: Pseudophryne (Jacobson 1963, Woodruff 1972), Crinia (Gollman 1991), Geocrinia (Gollman \& Gollman 1991), and Kyarranus (Watson \& Martin 1973, Anstis 1981). However, these are not useful under field conditions, either because illustrations are not provided for the stages that diverge from those identified by Gosner (1960), or because insufficien detail on external morphology is presented. Although the construction of our staging table was motivated by the need to identify stages under field conditions, and the rable is not primarily intended for comparative studies, sufficient observations were made to conclude that the developmental morphology of $B$. nimbus closely parallels that detailed by de Bavay (1993) for the limnodynastine Kyarranus sphagnicolus, a foam-nesting species with a similar life history. A modified version of de Bavay's staging could be used in the laboratory for Bryobatrachus, but it is not helpful for fieldwork. Because B. nimbus is non-feeding and lacks a mouth disc, particular difficulties are likely in the interpretation of Stages $24 b-26$ and 34 of de Bavay (1993) which utilise the development and disappearance of the prominent horny jaws of $K$ sphagnicolus.

Terrestrial anuran larvae have generally retained the morphology of the free-swimming, feeding ancestral larvae (de Bavay 1993), al though morphological divergence, such as the atrophy of feeding structures and the development of supplementary respiratory surfaces, can be pronounced in some direct-developing species (e.g. Eleutherodactylus cogui [Townsend \& Stewart 1985]). Bryobatrachus nimbus larvae appear to possess both kinds of adaptation, since they cannot feed and the long vascularised tail may act as a respiratory surface. In addition, $B$. nimbus exhibits some additional characteristics commonly found in directdeveloping larvae: the absence of egg pigmentation (Duellman \& Trueb 1994) and encapsulation in the vitelline membrane well into development (Salthe 1963).

In summary, we conclude that, while the reproductive mode employed by $B$. nimbus is rare but not unique within the global amphibian context, the combination of individual reproductive parameters is distinctive and does not occur in any other Australian species. The most unusual characteristics of larval development in $B$. nimbus are the large egg capsules and the year-long terrestrial larval development period. Larval development times of other populations of $B$. nimbus, located from calling surveys (Ziegeler 1994) are unknown but, given that B. nimbus occurs across an altitudinal range of $30-1100 \mathrm{~m}$ (Ziegeler 1994), it would be interesting to determine to what extent larval lifespan is temperature mediated. Our staging table will enable the length of larval development times in other populations of this unusual frog to be determined.

\section{ACKNOWLEDGEMENTS}

This work was supported by financial assistance from a Tasmanian World Heritage Area Fauna Conservation Research Grant. We thank all those who assisted in the field, especially Bobby Mitchell. Eggswere collecred under Permit FA 95090.

\section{REFERENCES}

ANSTIS, M., 1981: Breeding biology and range extensions for the New South Wales frog Kyarranus sphagnicolus (Anura: Leptodactylidae). Aust. J. Herpetol. 1: 1-9.

DE BAVAY, J.M., 1993: The developmental stages of the sphagnum frog, Kyarranus sphagnicolus Moore (Anura: Myobatrachidae). Aust. J. Zool. 41: 151-201.

DUEllian, W.E., 1985: Reproductive modes in anuran amphibians: phylogenetic significance of adaptive strategies. S. Afr. J. Sci. 81: 174-178.

Duellman, W.E. \& Trueb, L., 1994: BIOLOGY OF AMPHIBIANS. The John Hopkins University Press, Baltimore (1986: McGraw-Hill).

GENTILLI, J., 1972: AUSTRAIIAN CLIMATE PATTERNS. Nelson, Melbourne.

Gollman, B., 1991: A developmental table for Crinia signifera Gillard, 1853. Alytes 9: 51-58.

Gollman, B. \& Gollman, G., 1991: Embryonic development of the myobatrachine frogs Geocrinia laevis, Geocrinia victoriana, and their natural hybrids. Amphibia-Reptilia 12: $103-110$

GOSNER, K.L., 1960: A simplified table for staging anuran embryos and larvae with notes on identification. Herpetologica 16 : 183-190.

HOAR, W.S. \& HICKMAN, C.P., 1975: A IABORATORY COMPANION FOR GENERAL AND COMPARATIVE PHYSIOLOGY. 2nd Ed. Prentice-Hall, New Jersey.

JACOBSON, C.M., 1963: Developmental variation within the genus Pseudophryne Fitzinger. Proc. Linn. Soc. N.S.W. 88: $277-286$

Littlejohn, M.J., Roberts, J.D., Watson, G.F. \& Davies, M., 1993: Family Myobatrachidae. In Glasby, C. J., Ross G.J.B. \& Beesley, P.L. (Eds): FAUNA OF AUSTRALIA. VOL. 2A: AMPHIBIA AND REPTILIA. Australian Government Publishing Service, Canberra: 41-57.

Maln, A.R., 1957: Studies in Australian Amphibia. 1. The genus Crinia Tschudi in south-western Australia and some species form south-eastern Australia. Aust. J. Zool. 5: 3055.

Martin, A.A., 1967: Australian anturan life histories: some evolutionary and ecological aspects. In Weatherly, A.H. (Ed.): AUSTRALIAN INLAND WATERS AND THEIR FAUNA. Australian National University Press, Canberra: 175-191. 
RoberTs, J.D., 1981: Terrestrial breeding in the Australian leptodactylid frog, Myobatrachus gouldii. Aust. Wildl. Res. 8: 451-62.

Roberts, J.D., 1984: Terrestrial egg development and direct development in Arenophryne rotunda, a myobatrachid frog from coastal sand dunes at Shark Bay, Western Australia. Aust. Wildl. Res. 11: 191-200.

Roberts, J.D., Wardell-Johnson, G. \& Barendse, W., 1990: Extended descriptions of Geocrinia vitellina and Geocrinia alba (Anura: Myobarrachidae) from south-western Australia, with comments on the status of G. Lutea. Rec. West. Aust. Mus. 14: 427-437.

Rounsevell, D.E., Ziegeler, D., Brown, P.B., Davies, M. \& LitTLEjOHN, M.J., 1994: A new genus and species of frog (Anura; Myobatrachinae) from southern Tasmania. Trans. R. Soc. S. Aust. 118: 171-185.

Salthe, S.N., 1963: The egg capsules in the Amphibia. J. Morphol. 113: 161-171.

Scotr, E.O.G., 1942: A new Hyla from Cradle Valley, Tasmania, Rec. Q. Vict. Muss. 1: 5-11.

SEYmour, R.S. \& RoberTs, D.J., 1995. Oxygen uptake by the aquatic eggs of the australian frog Crinia georgiana. Physiol. Zool. 68: 206-222.
Swain, R., Marker, P.F. \& Richardson, A.M.M., 1988: Comparison of the gill morphology and branchial chambers in two fresh-water crayfishes from Tasmania: Astacopsis franklinii and Parastacoides tasmanicus. J. Crust. Biol. 8: 355-363.

Townsend, D.S. \& Stewart, M.M., 1985: Direct development in Eleutherodactylus coqui (Anura: Leptodactylidae): a staging table. Copeia 1985: 423-436.

TYLER, M.J., 1962: On the preservation of Anuran tadpoles. Aust. J. Sci. 25: 222.

Watson, G.F. \& MArTin, A.A., 1973: Life history, larval morphology and relationships in Australian leptodactylid frogs. Trans. R. Soc. S. Aust. 97: 33-44.

WoOdrufF, D.S., 1972: The evolutionary significance of hybrid zones in Pseudophryne (Anura: Leptodactylidae). Unpubl. PhD thesis. Univ. Melbourne.

Ziegeler, D., 1994: Distribution and habitat of the moss froglet, a new undescribed species from south west Tasmania. Tasm. Nat. 116: 31-37.

(accepred 14 May 1996) 